\title{
Dificuldades para implementação da lei 10.639: A influência dos valores religiosos sobre os temas apresentados no texto da lei
}

Glauber Henrique Corrêa Rocha

\section{Resumo}

Este artigo consiste numa apresentação dos principais resultados obtidos através de entrevistas concedidas por professores de Geografia, no que tange à influência de valores religiosos sobre a aplicação dos conteúdos apresentados pela lei 10.639. A análise que será apresentada busca demonstrar as dificuldades destacadas pelos docentes dessa disciplina no que se refere ao debater sobre o Continente Africano no ambiente escolar. Destacamos este último como sendo o palco onde o currículo praticado é construído e também onde pode ser observada a ação dos valores religiosos expressos através da prática de professores, alunos e funcionários - que, em alguns casos, apresentam-se como fatores que dificultam o desenvolvimento dos temas apresentados pela lei.

Palavras-Chave: Lei 10.639; ambiente escolar; currículo praticado; valores religiosos.

\begin{abstract}
This article is a presentation of the main results obtained through interviews granted by teachers of Geography, regarding the application of content provided by law 10,639. The analysis that will be presented seeks to demonstrate the difficulties highlighted by the teachers of this discipline with regard to the debate on the African continent in the school environment. We emphasize the latter as stage where the curriculum practiced is built well where it can be observed the actions of religious values - expressed through the practice of teachers, students and employees - in some cases, appear as factors that hinder development of the themes presented by the law.
\end{abstract}

Key-Word: 10.639 Law; school environment; curriculum practiced; religious values.

\section{A Geografia buscando seu espaço no debate}

A lei 10.639 foi promulgada em janeiro de 2003, pelo então presidente Luiz Inácio "Lula" da Silva, e torna obrigatório o ensino sobre História e Cultura Afro-Brasileira. Graças à aprovação desta houve uma reformulação na (LDB) através dos artigos 26-A e 79-B.

No que tange o texto da lei é possível constatar a existência de uma contradição no $2^{\circ}$ parágrafo este indica que os conteúdos indicados devem ser trabalhados em todo o currículo escolar e logo depois destaca as áreas de 


\section{REVISTA TAMOIOS}

Educação Artística, Literatura e História como disciplinas que devem debater os temas relacionados com a África de forma mais especial.

$\S 2^{\circ}$ Os conteúdos referentes à História e Cultura Afro-Brasileira serão ministrados no âmbito de todo o currículo escolar, em especial nas áreas de Educação Artística e de Literatura e História Brasileiras.

Na contramão desta contradição há o debate que gira em torno do fato de outras disciplinas também possuírem condições de se engajarem no debate sobre esse tema. É importante destacar que as disciplinas escolares são ferramentas utilizadas na educação escolar e esta última tem uma importância bastante expressiva no que diz respeito à superação das desigualdades raciais e do racismo. Tomando-se o ambiente escolar como um dos principais ambientes de socialização pode-se compreender que este influencia na formação de personalidades, bem como nas visões de mundo e na forma como o indivíduo se percebe/posiciona neste.

A Geografia, assim como outras disciplinas, exerce um papel muito importante na formação de referenciais posicionais do indivíduo no mundo. A noção de mundo aqui apresentada está em concordância com Santos (2007):

[...] falamos de "mundo" como uma noção que atenta para a complexidade espaço-temporal das relações sociais do/no espaço vivido, relações que o constroem, o influenciam, são influenciadas por ele, enfim, o constituem, bem como são por ele e nele constituídos, numa relação de imanência que torna individuo e mundo algo tão indissociáveis quanto estrutura (social, econômica, espacial, etc.) é em relação à experiência. (P. 25)

Essa concepção de mundo apresentada acima dialoga com o que Campelo (2006), apresenta como sendo identidade:

Identidade aqui é entendida como uma imagem (representação de si)
construída ao longo de experiências de troca com família, a escola, o
grupo de trabalho ou a coletividade a que um indivíduo pertence.
Também se refere a um processo de autoclassificação que envolve
manipulação de categorias que incluem os indivíduos (identidade
ideológica), como sentimento de pertença a um grupo. Nesse sistema
é possível perceber as fronteiras nítidas estabelecidas, por exemplo,
entre credos religiosos, aparência física (cor da pele, vestimenta,
tatuagem, postura corporal, etc.), atitude ideológica (partido, religião e
comunidade) que por sua vez ajudam a promover ou não a inserção
(individual/coletiva) nas diferentes camadas de uma sociedade. (P.
145)

A escola é um ambiente extremamente favorável para o desenvolvimento tanto da visão de mundo como da identidade, e a Lei 10.639 surge como um meio para possibilitar a apresentação de uma visão de mundo e de uma identidade negra, não eurocêntrica - além de buscar resgatar a autoestima de grande parte da população brasileira que é negra, mas que não se reconhece nem se orgulha disso.

Sendo assim, a Geografia tem disputado condições para assumir espaço entre as disciplinas que apresentam condições de discutir as questões relacionadas à História da África e dos africanos, a luta dos negros no Brasil, a cultura negra brasileira e o negro na formação da sociedade nacional. 


\section{Experiência dos professores}

Para construir este artigo tomamos como ponto de partida o relato de dez professores de Geografia. Estes foram organizados em dois grupos ambos com cinco professores. Um dos grupos foi formado por professores que são acompanhados pela pesquisa "A Lei 10.639 e o Ensino de Geografia" e o outro por docentes que não fazem parte deste. Aplicamos a metodologia de entrevistas estruturas, estas foram conduzidas a partir de um Roteiro Básico composto por dez perguntas que se agrupam em seis blocos de interesse, a saber: localização da escola,ação das organizações religiosas,postura da direção da escola; postura do professor, postura do aluno econteúdos.

Partimos do entendimento de que os valores religiosos estão presentes no ambiente escolar e se manifestam através do habitus ${ }^{1}$ dos professores, alunos e funcionários.

Oito dos professores entrevistados afirmam que tratar o conteúdo relacionado ao Continente Africano e a sua cultura em sala de aula resulta em algumas situações complicadas. Alguns desses professores apresentaram experiências que demonstram as dificuldades que aparecem ao abordar questões ligadas à temática racial ou até mesmo sobre a África em suas aulas. Essas dificuldades decorreram de posturas preconceituosas de alunos devido aos seus posicionamentos religiosos e também de professores. Sendo assim, visualizamos aqui um exemplo de conteúdo que está inserido no currículo da disciplina de Geografia que sofre a ação dos discursos religiosos que estão presentes nas escolas.

Para demonstrar como isso se materializa na escola apresentamos fragmentos da fala de alguns dos professores entrevistados sobre a experiência que vivenciaram ao tratar desse tema em suas aulas e também na relação com outros professores e funcionários. O objetivo é apresentar elementos que contribuem para a formação do Currículo Praticado ${ }^{2}$, sabendo que este resulta da associação de diversos fatores que podem extravasar a sala de aula e até mesmo a escola. Abaixo apresentamos um quadro com os nomes (fictícios) dos professores, assim como o vinculo religiosa dos mesmos.

\begin{tabular}{|l|l|}
\hline NOME & RELIGIÃO \\
\hline Sandra & Católica (não praticante) \\
\hline Aline & Umbandista \\
\hline Carlos & Agnóstico \\
\hline Débora & Católica \\
\hline Flávia & Evangélica \\
\hline Elaine (pesquisa.) & Sem Religião \\
\hline Patrícia (pesquisa.) & Sem Religião \\
\hline Gustavo (pesquisa.) & Sem Religião \\
\hline & \\
\hline Elias (pesquisa.) & Evangélico \\
\hline Glória (pesquisa.) & Sem Religião \\
\hline
\end{tabular}

Fonte: autor

Apresentamos como ponto de partida, a fala de uma professora que indica que as Organizações Religiosas podem ser a origem dos discursos preconceituosos relacionados ao Continente Africano. A professora Patrícia se referindo a uma organização de origem cristã diz: 
Eles falaram que havia fome na África e havia muitas guerras lá por conta deles serem macumbeiros, com essa expressão: macumbeiro, por serem feiticeiros. Eu falei: meu Deus. Então eu falei: caramba, isso é uma anti-aula de Geografia, de História, de Política, de tudo. Então, ali é alienação total.

Esse fragmento busca ressaltar o fato das Organizações Religiosas apresentarem discursos que são absorvidos por aqueles que estão associados a elas. Estes levam para a escola o habitus que foi construído dentro do campo ${ }^{3}$ religioso e ao entrarem em contato com o conteúdo científico sobre o tema, nesse caso África, sentem-se em um contexto de conflito e é nesse contexto que as características do habitus tornam-se mais visíveis.

Para exemplificar como os alunos expressam isso na escola 0 professor Elias ratifica que sobre alguns pontos, principalmente os mais dramáticos e drásticos, os alunos têm uma visão muito fatalista das coisas, por exemplo, a África é pobre porque Deus quis, porque eles são macumbeiros, eles não são cristãos.

É comum, ao tratar sobre o Continente Africano ou sobre a temática racial, que haja a associação com as questões religiosas. Com base nas entrevistas feitas com os professores foi possível observar que a maioria dos alunos faz a relação do debate sobre o Continente Africano com a Macumba, essa associação tende a se expressar na fala dos alunos:

[...] eles cansam de falar: professora a senhora é macumbeira. Talvez porque eu use trança afro. Eu acho que sou a única professora da escola que procuro trabalhar o Continente Africano com mais qualidade, eu falo muito de África e ai eles associam isso com a Macumba, que eu sou macumbeira. Professora Patrícia

De acordo com o professor Eliashá casos em que existe a associação da África como origem dos demônios, esse professor citado acima relata que essa foi a conclusão que alguns dos alunos construíram a partir de uma pesquisa feita sobre o racismo na Igreja:

[...] eles falaram: - Não professor olha só, as entidades africanas são relacionadas ao diabo. É o diabo, são demônios na verdade. Então você na verdade atribui você cria, você dá uma origem geográfica aqui eles falando - uma origem geográfica pra entidades que estão em outra dimensão, os caras são da Africa, entende? O demônio está na África. (grifo nosso)

A professora Glória apresenta algo que vivenciou em sala de aula ao dar início ao debate sobre o Continente Africano e consequentemente sobre a temática racial. Na fala abaixo se observa a relação que o aluno faz entre a cor da pele e a religiosidade de origem africana:

Agora quando vai se tratar, e aí particularmente, de um assunto relacionado às questões raciais ai pega o lado religioso, então existe "um certo", uma certa negação, mas não é uma negação, quer dizer já aconteceu esse ano, de um menino dizer: Ah se for tratar de - foi horrível o que ele falou - se for tratar de preto vai falar de Macumba, então eu não quero saber. (grifo nosso). Glória

Além dessa relação entre África e Macumba, na escola também existem os conflitos decorrentes da intolerância religiosa direcionada contra os 


\section{REVISTA TAMOIOS}

seguidores de religiões de origem africana, por estas serem rotuladas como diabólicas.

Como exemplo de intolerância, no ambiente escolar, direcionado aos seguidores de religiões de origem africana apresenta-se a série de reportagens (Inimigos da Fé) publicadas pelo Jornal Extra, com destaque para a que recebeu o título "Os herdeiros da intolerância"Monteagudo(2009). Nessa reportagem foi apresentado o caso de Felipe Gonçalves Pereira, de 13 anos, que foi chamado de "filho de demônio", por uma professora ${ }^{4}$ na frente dos outros alunos após ter mostrado aos colegas o fio de contas ${ }^{5}$ que estava usando por baixo do uniforme. A mãe de Felipe descreve o ocorrido da seguinte forma: Ela diz para o meu filho que ele é filho do capeta. Ela o desacata na sala, grita com ele e o expulsa, dizendo que a aula dela, ele não vai assistir. Em decorrência dessa experiência o adolescente pensou até em cometer suicido: - Eu pensava: Não quero mais viver. A professora me chamou de "filho do capeta". Não sou isso - diz Filipe. Nessa mesma reportagem é apresentado outro exemplo de intolerância, dessa vez entre os alunos, nesse caso trata-se da experiência vivenciada por um adolescente de 14 anos.

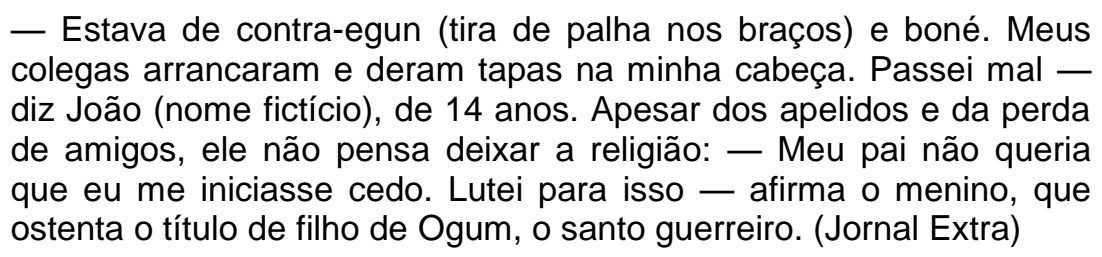

Essa reportagem demonstra que muitas vezes os professores não estão preparados para trabalhar com alunos que seguem alguma religião de vertente africana, e essa dificuldade possivelmente pode ser expressa na forma como esse docente trata o conteúdo relacionado à África em suas aulas.

O debate sobre a religiosidade influencia tanto a dinâmica da escola que a professora Glória relata o fato ocorrido devido à organização da festa de formatura dos alunos de uma das escolas onde trabalha. O tema da festa estava associado à temática racial e à África, logo seriam utilizados símbolos representativos da cultura africana, em decorrência disso foi apresentada a experiência que segue:

Então há uma influência na dinâmica da escola aqui, tipo para eu tratar as questões raciais é complicado, por exemplo, pediram para eu fazer o convite, mas não tem liberdade: - Não põe determinadas coisas! Enfeites que iam fazer parecer... que não vão poder ter senão eles vão dizer que está relacionado a Macumba e assim, não participam e ai na festa de formatura deles, eles não viriam [...]. Professora Glória

Outro exemplo que demonstra a religião influenciando o ambiente escolar foi retirado da entrevista feita com o professor Elias:

Em Caxias, inclusive, teve um professor, nessa época eu não lecionava lá ainda, mas eu fiquei sabendo, que um professor fazendo lá um evento de 20 de novembro chamou lá a mãe-de-santo dele pra fazer uma cerimônia pra, enfim, compartilhar a religião dele com os alunos. 


\section{REVISTA TAMOIOS}

Ainda tratando sobre a questão da religiosidade a professora Glória apresenta o fato, ocorrido em outra escola, de um grupo de professores "tacharem" um aluno de homossexual devido a sua filiação em uma religião de origem africana:

No nono ano tem um menino, o Guilherme (nome fictício) ele é um aluno extremamente inteligente, mas muito preguiçoso - desleixado. $E$ ai alguns professores, não os alunos, os alunos não o tratam diferente, [...] às vezes sai: É porque ele, Guilherme está faltando porque está na macumba. Ele é "candomblecista" - que fala - ele está ligado ao Candomblé. É um aluno novo, dever ter uns 14 anos e alguns professores falam que o problema dele é porque ele está ligado a essa religião. [...] Então tem alguns professores que estão tachando, estão determinando um aluno a partir da religião dele, já estão tachando ele de várias coisas e até de homossexual. (grifo nosso).

No que diz respeito à utilização de símbolos que remetem a religião o professor Gustavo apresentou o relato de uma experiência que realizou em uma de suas turmas. O objetivo foi provocar e analisar a reação dos alunos, para tal Gustavo, entrou em sala vestindo uma camisa com a seguinte frase: "Só acredito em deus que dança", o resultado foi o seguinte:

A reação foi engraçada, era uma turma que tinha muitos alunos evangélicos que tinham essa demonstração de... um certo preconceito com outras formas religiosas e comportamentos diferentes dos deles. E ai eu tinha essa camisa, que eu ganhei de um amigo, e ai eu resolvi ir com essa camisa. E ai assim a reação foi engraçada, porque em um primeiro momento eles ficam espantados, ninguém falou nada, até que uma aluna mais desaforada, assim desaforada entre aspas, foi e perguntou o que era aquela camisa, e eu falei que era uma camisa com todos os orixás e não sei o que... Ai eles ficaram rindo, alguns com olhar assustado, mas com o tempo passou. Eu acho que eles entenderam que era só uma camisa. Que era só uma provocação pra eles [...].

Retomando a entrevista feita com a professora Patrícia, observa-se a afirmação feita que busca destacar que a visão pejorativa sobre a África não é algo recente, mas faz parte de uma ação dos colonizadores europeus que tinham como origem religiosa o Cristianismo. Essa ação tinha como objetivo valorizar os conhecimentos europeus em detrimento dos conhecimentos produzidos na África:

Quando eu estou trabalhando o Continente Africano e pergunto para eles: O que vocês entendem da África? Eles falam logo: Macumba, Feitiçaria. Por conta não só da Igreja Católica, mas das Igrejas Protestantes também, ai eu tenho que falar que não existe religião certa nem errada isso é uma escolha. E se hoje o país é cristão isso é por conta de uma colonização européia, eurocêntrica. Os habitantes originais dessa terra, não eram, não eram, Católicos, não eram Protestantes, não eram nada. Nada disso. Isso foi uma imposição. Não houve só o genocídio indígena, houve um genocídio cultural e religioso também. Professora Patrícia

Um dos principais objetivos da Lei 10.639 é justamente confrontar essa visão eurocêntrica de formação do mundo buscando validar outras origens de 


\section{REVISTA TAMOIOS}

conhecimentos, principalmente, os que foram produzidos por africanos, bem como buscar a valorização da identidade do negro que hoje é fortemente influenciada pela visão européia. Sobre a valorização da identidade do negro a professora Patrícia afirma:

[...] os negros só sobreviveram aqui no Brasil por conta dessa cultura e da religião deles, dessa identidade deles. A partir do momento que cada povo perde a sua identidade ele é destruído. A identidade afro tem que ser preservada pra sobrevivência da população, se os negros aqui no Brasil não tivessem preservado sua identidade eles teriam sido exterminados. Então é importante preservar a identidade. Professora Patrícia

Retomando agora a questão central desse trabalho que é a influência dos discursos produzidos pelas Organizações Religiosas na formação do Currículo Praticado e compreendendo que os alunos têm importante papel na formação desde currículo foi perguntado aos professores: Normalmente qual é a postura dos alunos no que diz respeito a visões religiosas divergentes a deles?E algumas respostas ratificaram o preconceito que existe contra o tema África que, normalmente, perpassa pela questão dos valores religiosos:

Eles só implicam com religiões africanas. A única religião que eles têm preconceito é com relação às religiões africanas. Em relação aos outros tipos: se for católico não tem preconceito, se for protestante não tem, se for budista não tem, se for [áudio não compreendido] não tem, mas se for a africana tem. Professora Patrícia

Outro exemplo extraído da resposta de outro professor para essa mesma pergunta ratifica o fato de que os alunos têm uma visão negativa sobre a cultura africana:

Assim eles são... demonstram até um certo preconceito com relação a outras formações religiosas existentes. Principalmente as religiões relacionadas a questão afro, a macumba, que eles chamam de macumba, que é a umbanda. Ou a outra, que eu esqueci no momento agora, que eles têm um preconceito muito grande. Assim eles ridicularizam qualquer coisa relacionada a isso, a gente tenta demonstrar que isso não deve ser feito, mas isso vai de uma formação muito externa, fora da escola, de pai, de mãe, da representação que pai e mãe têm em relação a esses tipos de religião. A gente tem que tentar demonstrar que tem que respeitar as diferenças. Professor Gustavo

Outro entrevistado apresentou a seguinte resposta para essa mesma pergunta:

Eles demonizam, satanizam mesmo, entende? [...]Mas o cara diz: Eu sou espírita. Mas que espiritismo você pratica? Não eu sou de Umbanda e tal, e ai você já percebe que a rapaziada já olha com olhas de crítica, de temor: esse cara é um servo do diabo! Entende? Então geralmente eles tratam dessa forma. [...] Uma aluna de Ensino Fundamental, em Itaboraí, falou pra mim na aula: - Não professor é porque minha mãe é de Umbanda e eu também... - E ela é macumbeira! Ela é macumbeira! E ai começaram a querer "sacanear" a menina[...]. Professor Elias 


\title{
REVISTA TAMOIOS
}

Tomando como base as citações acima podemos compreender que os alunos já chegam à sala de aula com uma concepção formada sobre o que é o Continente Africano, bem como sobre a sua cultura. Essa concepção interfere de várias formas na prática do professor que buscar abordar a temática racial e o conteúdo relacionado à África em sua aula de Geografia.

Até aqui só foram apresentados exemplos de fatores que se posicionam de forma contrária à aplicação do conteúdo da África, mas o próximo exemplo demonstra o outro lado. Nele há um destaque sobre a ação de um aluno que não se sente interessado pelo conteúdo apresentado pelas disciplinas escolares até o momento que consegue se identificar com um tema que dialoga com a sua posição religiosa. Para isso retorna a fala da professora Glória que trata do aluno Guilherme:

\begin{abstract}
É o único aluno que eu estou associando, que pelo menos eu, porque ele assume: Não eu sou, eu vou lá no Candomblé! O meu Pai de Santo. Uma vez eu estava trabalhando África - isso foi no ano passado - com ele, com a turma na verdade e ai ele ficou muito interessado no assunto, foi o único assunto que interessou ele [...]. (grifo nosso)
\end{abstract}

\section{Conclusão:}

A concepção prévia que os alunos têm sobre o continente africano é construída, normalmente, em contextos externos a escola, dentre estes estão os que chamamos nesse trabalho de Organizações Religiosas. Os discursos e valores divulgados por essas organizações acabam entrando na escola e acabam influenciando na prática do professor que pode vivenciar alguma das experiências apresentadas acima e pode deixar de tratar ou supervalorizar o debate sobre a África devido às questões que estão relacionadas à religiosidade.

Sendo assim, compreende-se a partir dos relatos, que o professor de Geografia, ao se propor a aplicar, em suas aulas, o conteúdo apresentado na Lei 10.639 pode ser confrontado com possíveis questionamentos que se originam em questões religiosas. Esses questionamentos podem até mesmo pôr à prova o seu posicionamento religioso, indicando que os valores que são divulgados dentro do campo religioso são reais e estão presentes na escola e têm influência sobre a prática do professor em sala de aula.

Cabe ressaltar que independente do posicionamento religioso de professores, alunos e funcionários da escola, é extremamente importante que haja total cuidado, atenção e principalmente respeito entre as pessoas que não compartilham da mesma convicção religiosa.

\section{Notas}

I - Santos apud Rocha (2011), habitus consiste em uma matriz geradora de comportamentos, visões de mundo e sistemas de classificação da realidade que se incorporam aos indivíduos (ao mesmo tempo em que se desenvolvem neles), tanto no nível das práticas, como no da postura corporal desses mesmos sujeitos. Desse modo, o habitus é apreendido e gerado na sociedade e incorporado pelos indivíduos que a compõem. 


\section{REVISTA TAMOIOS}

II - Alves apud Santos (2007) [...] o currículo não se resume àquilo que é determinado pela via oficial. Na verdade, existem elementos que se refletem na prática quotidiana da escola, na qual participam, sobretudo, professores e alunos, mas também outros atores da comunidade educativa, e que ajudam a construir aquilo que denominamos por currículo praticado. Consideramos, nesse sentido, que para se entender o conceito de currículo é preciso ter em atenção à forma como esses processos se desenrolam na prática. É no espaço-escolar que se desenha o currículo - através de acordos e mudanças que é necessário rever quase quotidianamente, e não através de determinações legais.

III - O campo é o contexto no qual são desenvolvidos os discursos que promovem o habitusque por sua vez divulgam os valores produzidos no interior do campo

IV - A reportagem não apresenta qual era a disciplina que a professora ministrava.

V - São colares normalmente feitos de miçangas coloridas de acordo com o orixá, Inkice, Vodun, cada fio de conta tem um significado, através do fio de conta é que se pode saber o grau de iniciação de uma pessoa do candomblé, e a que nação pertence.

\section{Bibliografia:}

CAMPELO, Marilu Márcia. Cultura, Religiosidade Afro-Brasileira e Educação formal no Pará - os valores culturais afro-brasileiros chegam às salas de aula? In: Dimensão da inclusão no Ensino Médio: mercado de trabalho, religiosidade e educação quilombola. Brasília: UNESCO, 2006, p.141-163.

MONTEAGUDO, Clarissa. Inimigos da fé. Os herdeiros da intolerância. Jornal Extra. Rio de Janeiro, 25 jan. 2009. Caderno Geral, p. 3.

ROCHA, Glauber Henrique Corrêa.Discutindo a influência das organizações e dos habitus religiosos sobre a prática do professor de geografia: fatores que regulam o currículo praticado - 2011.

SANTOS, Renato Emerson dos. O ensino de Geografia e as relações raciais: reflexões a partir da Lei 10.639. In: SANTOS, Renato Emerson (org.). Diversidade, espaço e relações étnico-raciais: o negro na Geografia do Brasil. Belo Horizonte: Ed. Autêntica, 2007, p.21-40. 